\title{
Sobre la voz murciana merancho y los topónimos Belinchón (Cuenca) y Maranchón (Guadalajara)
}

\author{
Emilio Nieto Ballester \\ Depto. Filología Clásica UAM \\ emilio.nieto@uam.es
}

Resumen: Se estudia el origen de la palabra murciana merancho, "acequia o azarbe secundario". La explicación se fundamenta en su comparación con otros muchos topónimos procedentes de Castilla-La Mancha, como Maranchón (Guadalajara), Meranchas (El Recuenco), Arroyos de Maranchel (Yunque de Henares). A continuación se compara todo el material léxico-toponímico citado con otra serie de topónimos que muestran un sustantivo merdancho o formas derivadas, del tipo Mierdanchel (Canalejas del Arroyo, Cuenca), Arroyo de Merdancho (Talavera de la Reina, Toledo), etc. La presencia en todos los casos del lexema *merd- nos sirve para comprender el origen y significado de todos ellos. Se trata de derivados de la palabra mierda, merda a la que se ha añadido el sufijo -ancho. La viabilidad de la propuesta se ratifica por la existencia de otros derivados de lat. merda indudables, como Arroyo Merdero (Higuera de la Serena, Badajoz), Río Merdero (Albornos, Ávila), etc. Se ha alterado merdancho en merancho para romper la asociación con un vocablo malsonante. Estos procesos son frecuentes en toponimia.

Palabras clave: toponimia española; dialectología española; léxico; sufijación; eufemismo.

\footnotetext{
Abstract: The aim of this paper is to study the origin of the word merancho (Murcia), "ditch or secondary irrigation canal". The explanation is based on comparing this voice with many place names, mainly from Castilla-La Mancha, as Maranchón, Meranchas (El Recuenco), Maranchel (Yunque de Henares, Guadalajara). Afterwards, all this lexical material quoted before is compared with another large number of place names which show without doubt a noun merdancho or similars, as Mierdanchel (Canalejas del Arroyo, Cuenca), Arroyo de Merdancho (Talavera de la Reina, Toledo), etc. The presence in all cases of the stem * merd- serves us to understand the origin and

》 Nieto Ballester, Emilio. 2015. "Sobre la voz murciana merancho y los topónimos Belinchón (Cuenca) y Maranchón (Guadalajara)". Quaderns de Filologia: Estudis Lingüístics XX: 111-121. doi: 10.7203/qfilologia.20.7515
} 
meaning of all of them. We are dealing with the word merda, "shit", to which was added the ending -ancho. In the phonetic order it is to be noted that merdancho has been altered in merancho in order to break the association with an objectionable word. These removal processes of bad language are not infrequent in place names.

Keywords: Spanish toponymy; Spanish dialectology; lexicon; suffixation; euphemism. 
0 . Es un hecho cierto que la explicación de términos dialectales oscuros y restringidos a zonas limitadas del territorio de una lengua dada puede apoyarse en alguna medida en el estudio detallado de la toponimia, toda vez que muy a menudo muestra la pervivencia en el terreno de voces que han desaparecido de su uso como términos vivos. En este orden de cosas, el objetivo del presente trabajo es proponer una hipótesis sobre el origen de la voz murciana merancho utilizando el material toponímico a nuestra disposición. Al mismo tiempo, y de manera inversa, la explicación correcta de esta voz dialectal permite el esclarecimiento de muchos topónimos extendidos por zonas de España más amplias que las que actualmente presenta el vocablo que, a nuestro juicio, está en su origen.

1. El sustantivo merancho es conocido al menos en algunas zonas de la región de Murcia ${ }^{1}$. Se trata de un término técnico de la irrigación, de especial importancia en la vega del río Segura, en donde los vocablos vinculados al riego son muy abundantes por razones obvias. $\mathrm{Su}$ significado es algo así como "acequia o azarbe secundario que devuelve al río o canal principal aguas ya utilizadas o sobrantes del riego", "cauce mayor de avenamiento"2. Hasta donde nos es conocido no se ha propuesto ninguna explicación sobre su origen y etimología. Como era de esperar, la toponimia de la región de Murcia nos ofrece abundante presencia del sustantivo, bien con la forma citada, merancho, bien con variantes merencho, *melencho, *melincho, estas dos últimas exclusivamente con forma sufijada en -ón, que parece en principio aumentativa: Merancho de los Molinos (Murcia) Merancho (Murcia, Monteagudo),

\footnotetext{
* Este trabajo ha sido redactado en el marco del proyecto de investigación FFI201021807. El autor agradece a los otros miembros del proyecto sus aportaciones en la discusión conjunta de esta contribución. Los errores son de la exclusive responsabilidad de su autor Se agradece, por ultimo, a los informantes sus sugerencias, la mayor parte de las cuales ha sido tenida en cuenta.

${ }^{1}$ Hemos llevado a cabo un rastreo, sin pretensión de exhaustividad alguna, sobre la presencia de la palabra en algunos vocabularios dialectales de las regiones meridionales y centrales de España (Murcia, Castilla-La Mancha, Extremadura, Andalucía). Así, constatamos su ausencia en Toro 2007 (:1920), Alcalá 1998 (:1951), Chacón 1981, Gómez 1981, Serrano 1986, Calero 1987, Sánchez 1998.

${ }^{2}$ Este significado lo hallamos en la magnífica obra de García Soriano 1932: 83, que dice textualmente "lo mismo que landrona, cauce mayor de avenamiento". Recoge tanto merancho como meranchón. Ninguna de estas voces aparece recogida en el DRAE.
} 
con variante Merencho, Meranchón (El Raal), Meranchos (Alquerías), Merenchón (Águilas), con variantes Melenchón, Melinchón ${ }^{3}$.

2. A pesar de que, como es sabido, una parte muy notable del léxico especializado para la irrigación es de origen árabe (acequia, ace$\tilde{n} a$, azarbe, noria, etc.), la voz merancho con sus variantes *melencho, *melincho con seguridad no lo es ${ }^{4}$. El esclarecimiento de su origen debe reposar, a nuestro juicio, en la comparación con otros sustantivos documentados en otros territorios españoles, aunque ello sea como topónimos, no como voces vivas. En este orden de cosas, creemos que es importante la existencia de algunos topónimos del tipo Maranchón, población muy conocida de Guadalajara, Meranchas (El Recuenco, Guadalajara), Arroyo de Maranchel (Yunque de Henares, Guadalajara). Son importantes, porque, a nuestro juicio, nos muestran junto al mismo vocablo con una variante con vocalismo /a/ en la sílaba inicial, una forma femenina y otra diminutiva de aspecto mozárabe, puesto que Maranchel parece proceder de *Maranchiel, él mismo de *Maranche$l l o$, con la usual diptongación de /e/ y apócope que hallamos en tantos otros topónimos de zonas donde la presencia mozárabe es abundante 5 . Con todo, ciertamente estos topónimos de Guadalajara no aclaran en absoluto el posible origen del vocablo, pues la forma es, en lo esencial, la misma que la que muestran los topónimos murcianos. Como quiera que sea, parece sensato afirmar que esta primera capa toponímica, por así decir, no permite dilucidar el origen de la voz murciana, pero, al menos, incrementa el número de datos.

3. La explicación debe reposar en la comparación de unos y otros con otra serie, mucho más amplia, de topónimos, procedentes de varias regiones españolas, que ofrecen un aspecto algo distinto, pero en lo esencial igual. Aquí radica lo fundamental de nuestra hipótesis. Se trata, en efecto, de los muchos topónimos que muestran un sustantivo merdancho y derivados, como por ejemplo Arroyo de Mierdanchel (Canalejas del

\footnotetext{
${ }^{3}$ Los datos toponímicos murcianos proceden de González \& García 1998.

${ }^{4} \mathrm{Su}$ propio aspecto fonético parece descartar este origen. Naturalmente la palabra está ausente de los diccionarios de arabismos del español, como Corriente 1999.

${ }^{5}$ Compárese, así, topónimos como Leganiel (Cuenca), Cardiel de los Montes (Toledo), Muriel (Guadalajara), etc.
} 
Arroyo,Cuenca) ${ }^{6}$, Arroyo de Merdancho (Talavera de la Reina, Toledo), Pozo de Merdenchón (Santa Cruz de la Zarza, Toledo), Arroyo Merdancho (Villanueva de la Fuente, Ciudad Real), Río Merdancho (Almajano, Soria, afluente del Duero), Río Merdancho (Nájera, La Rioja), Merdancho (Ambas Aguas, La Rioja). La presencia en todos los casos de un lexema *merd-, con variante con presencia de /d/ frente a los anteriores topónimos en *mer- nos sirve así para comprender perfectamente el significado y origen de todos ellos. Se trata de derivados de la palabra mierda, merda, de origen latino, a la que se ha añadido el sufijo-ancho. Este sufijo puede haber tenido su origen en la unión de los sufijos -anco y el diminutivo -ulus. Aparece en pocos sustantivos y adjetivos y parece tener valor despectivo, más o menos visible en sustantivos del tipo rioj. cardancho, "cardillo áspero y grueso no comestible" [1802] (<* cardanculu < lat. carduus, -i), ast. lebranchu, "lebrato, liebre de cría" (<*leporanculu, < lat. lepus, -oris, "liebre"), etc. Es digno de mención también el hecho de que en ocasiones aparece unido a otros sufijos con valor en general aumentativo-despectivo o simplemente diminutivo-despectivo, como es el caso de cast. amolanchín, "amolador, el que tiene por oficio amolar instrumentos cortantes o punzantes", parlanchin; "persona que habla mucho y sin oportunidad, o dice lo que debía callar", camaranchón "desván de la casa, o lo más alto de ella, donde se suelen guardar trastos viejos" [1704], etc 7 .

El significado es obvio, pues se trata de ríos o arroyos de poco caudal en los que se acumulan detritos, suciedad, precisamente por su escaso caudal; son también arroyos que sirven de cloacas o desaguaderos de aguas sucias, malolientes. A partir de este significado originario, etimológico, es obvio que el significado murciano es una simple aplicación técnica para referirse a canales, a azarbes, que sirven precisamente para recoger el agua ya utilizada para el riego, el agua sucia. La explicación propuesta es natural, trivial, quizá poco poética, pero apegada a realidades concretas y sencillas, como es usual en la toponimia. La viabilidad de la propuesta se ratifica por la existencia de otros derivados de lat.

\footnotetext{
${ }^{6}$ Este primer topónimo tiene el interés de mostrar el sustantivo que sirve de base con diptongación no fonética. Nótese, al mismo tiempo, el tratamiento claramente mozárabe del sufijo *merdanchello $>*$ merdanchiello $>$ mierdanchiel . La cercanía al topónimo Arroyo de Maranchel, antes citado, es palpable.

${ }^{7}$ Los ejemplos proceden de Pharies 2002: 68-69. Para un estudio detallado del origen de este y de otros muchos sufijos en -nch, Pharies 1994.
} 
merda con sufijos más claros, totalmente indudables. Es el caso de las decenas de arroyos o cursos de agua, en general de escaso caudal, como Arroyo Merdero (Higuera de la Serena, Badajoz), Arroyo del Merdero (Barcarrota, Badajoz), Arroyo Merdero (Blacha, Ávila), Río Merdero (Albornos, Ávila) Merdero (Lanzahíta, Ávila), Huerto Merdero (Yebra de Basa, Huesca), Arroyo Merdero (Peñalén, Poveda de la Sierra, Guadalajara $)^{8}$, etc. Naturalmente, la imagen toponímica no es exclusiva de la toponimia en lengua española, pues aparece en general en todas partes. Así, en la toponimia catalana abundan ejemplos muy similares del tipo Merdançà, Merdançó, Merdançol, que reaparecen también la toponimia de Francia e Italia en formas muy similares (Merdançon en Francia, Merdarola en Italia, etc) ${ }^{9}$. En principio, la mayor parte de los topónimos explicados de esta manera no necesita una corroboración externa, sobre el terreno, al tratarse de arroyos o pequeños cursos de agua que, de forma natural, pueden haber sido designados de esta manera en razón de la escasez de sus aguas. En el caso del macrotopónimo de Guadalajara Maranchón, documentado como Meranchón, los datos de que disponemos son alentadores, pues se recuerda aún por parte de los vecinos la antigua presencia de una laguna de aguas estancadas y escasas en el mismo lugar en donde ahora se alza la población ${ }^{10}$. En el del topónimo conquense Belinchón, villa situada al oeste de la provincia, en la comarca de La Mancha, no lejos de Tarancón, debemos entender justamente que el nombre lo fue en origen de uno de los arroyos que cruza el término. Se da la circunstancia añadida de que esta villa es bien

\footnotetext{
${ }^{8}$ Los datos proceden de Cerveró 1975, López 1979 y Yago 1974.

${ }^{9}$ Los datos proceden de $O C$ 5: 257 con bibliografía. Es de interés señalar aquí que este grupo de topónimos catalanes fue identificado bien como tal ya por Balari 1899: 119122, pero se dejó llevar en lo que era una interpretación aparentemente muy fácil por grafías antiguas de estos topónimos del tipo Meritantem, Meritabilis, que justamente buscaban evitar la alusión brutal a los excrementos. Ello, aunque circunscrito en estos topónimos al ámbito gráfico, está justamente en la misma línea que lo que señalamos nosotros en este trabajo en torno a la modificación, no fonética estrictamente hablando, de algunos topónimos del tipo Belinchón, Maranchón y del mismo sustantivo merancho.

${ }^{10}$ Vid. Agustín 1985. Precisamente la plaza de la población, que se alza justo encima de la antigua laguna se llama hoy "del charco". Existe incluso un cuadro que la representa, en el archivo municipal. Para detalles sobre la cuestión son útiles Ranz 1996: 72, en donde se relaciona otras hipótesis sobre el origen del topónimo y Monge 1993: 105, que señala textualmente "se formó el pueblo alrededor de la misma laguna....". Puede encontrarse también información de interés en Serrano 1994: 275
} 
conocida por su producción de sal, que remonta al menos a tiempos romanos y prosigue en la actualidad. Esta producción se hacía en tiempos preindustriales por simple evaporación de aguas saladas. Un arroyo, probablemente el llamado hoy "Arroyo Salado", fuera de la temporada de producción, desplazaba los restos de sal y aguas sucias hasta su unión con el Tajo. Puede entenderse bien, por ende, que necesariamente este proceso de producción generaría un olor fétido y que, por otra parte, el arroyo que arrastraba los detritos de esta producción fuera llamado *Merdinchón, notablemente alterado hasta el actual Belinchón ${ }^{11}$.

Pocos problemas debería plantear esta explicación. Solo cabe alguna objeción desde el punto de vista estrictamente fonético ya que, ciertamente, una desaparición de /d/ en un grupo fonético [rd] como el que hemos señalado no es usual, no es regla fonética. Esta objeción es sin duda razonable, y lo es porque, efectivamente, no creemos que se trate estrictamente hablando de una evolución fonética. Somos de la opinión, bien al contrario, de que lo que se ha producido es una alteración, más o menos consciente, de la palabra motivada por el propio significado del término que es malsonante para muchos de los hablantes. Así las cosas, a menudo, no en todos los casos, se ha alterado merdancho en merancho para romper la asociación con el común mierda. Esta ha sido una de las alteraciones, pero ha habido otras, pues, según parece, en otros lugares se ha preferido una alteración consistente en la sustitución de /d/ por /1/, un fonema muy cercano, como parece constatarse en ejemplos como El Merlinchón (Cáceres). La unión, por tanto, de Belinchón y Merlinchón apunta, a nuestro juicio, a una forma *Merdinchón como origen común de ambos, aunque haya desaparecido /d/, como comentaremos más ampliamente abajo. Al margen de estos cambios fonéticos, encontramos aquí ante un sufijo -incho, que no sería, en última instancia, más que una variante del sufijo -ancho antes citado, como parece indicar el hecho de que a menudo algunos de los derivados conozcan homólogos en -ancho. Es el caso, por ejemplo, de cardencha, cardincha "planta bienal con las hojas aserradas, espinosas" junto a cardancho antes mencionado o del ext. herrinche "herrumbre" junto a león. ferrancho "trozo de hierro", etc ${ }^{12}$. Así pues, parece razonable considerar que *merdin-

\footnotetext{
${ }^{11}$ Puede verse detalles sobre la producción preindustrial de sal por evaporación y la historia de las salinas de Belinchón en Plata 2011. En lo que hace a la forma del topónimo puede ser útil recordar sustantivos comunes del tipo camaranchón.

12 Pharies 1994, 2004: 335-336.
} 
cho, *merdinchón convivieron junto a merdancho, *merdanchón. Estos cambios fonéticos más o menos extremados se han producido, como hemos señalado, para evitar la palabra malsonante, algo que no es raro en toponimia, más en general en el léxico ${ }^{13}$.

Circunscribiéndonos a la toponimia y al sustantivo que nos ocupa la toponimia catalana nos muestra algunos ejemplos que a nuestro juicio corroboran la verosimilitud de nuestra propuesta. Así, el nombre del río Merder, que pasa por las afueras de Vic, es pronunciado a menudo [madé] aunque en principio es imposible la desaparición de $/ \mathrm{r} /$ en este contexto en la lengua catalana; a partir de esta desarticulación de $/ \mathrm{r} /$ se ha escrito en ocasiones Meder, con lo que se habría disociado ya por completo el nombre del río de su étimo, que es obviamente el cat. merda; un caso más extremo aún es el de la población de Santa Eulàlia de Riuprimer, cuyo río fue denominado en origen Riumerder. En este caso se sustituyó directamente la palabra malsonante Merder por -primer, que guarda un parecido más o menos lejano con prim, "delicado, delgado ${ }^{14}$ ". Naturalmente no sería difícil poner otros ejemplos semejantes, pues es posible que algunos de los muchos Arroyo de la Miel

${ }^{13}$ Piénsese, así, en alteraciones "eufemísticas" del tipo córcholis, diez (:Dios), ostras (:hostias) etc. En el caso concreto de nuestra palabra, mierda, su sustitución por "miércoles" es frecuente en Nicaragua. Un ejemplo conocido en el campo toponímico es el del catalán Cavall Bernat, uno de los más impresionantes monolitos del macizo de Montserrat. No hay duda de que el topónimo Cavall Bernat, esto es, "Caballo Bernardo", aparentemente absurdo, es una alteración "eufemística" de una comparación muy expresiva, pues efectivamente la roca tiene la forma de un carall trempat, "carajo erecto". Hay otros Cavall Bernat en el territorio de habla catalana, naturalmente, siempre referidos a monolitos de roca conglomerada. Los datos catalanes proceden de $O C$ 3: 265. Pueden verse buenas fotografías de Cavall Bernat en la dirección http://ichn.iec. cat/bages/geologia/ImatgesGrans/cCavallBernat.htm. Por último, nos parece de interés mencionar aquí el caso más extremo de alteración, que consiste sencillamente en no mencionar la palabra, que el oyente, por lo demás, conoce. Encontramos así muchos casos del tipo Arroyo de Malnombre (Cardenete, Cuenca), Fuente de Malnombre (Villar de Olalla, Cuenca), etc. No estamos seguros de que aquí el nombre sea el mismo que está presente en merancho y derivados, pero ello es muy probable, toda vez que se trata de un arroyo en el primer ejemplo, de una fuente en el segundo. Para fuentes malolientes, compárese casos como Fuente Podrida (Cardenete, Cuenca), Fuenpodrida (Vellisca, Cuenca), Fuente Hedionda (Manilva, Málaga) o incluso el macrotopónimo Ampudia (Palencia) < lat. fonte putida. Para más ejemplos y explicación detallada de casos como Ampudia puede ser útil Nieto 2000.

${ }^{14}$ Los datos catalanes proceden de OC 6: 404 para Riu Merder / Merder; 2: 460, 5: 258, 6:281 en lo que hace a Santa Eulàlia de Riuprimer. 
que encontramos en España puedan haber sido Arroyo de la Mierda en origen $^{15}$.

4. Nuestra hipótesis es, pues, en lo esencial la señalada hasta aquí. Un sustantivo común del dialecto actual de Murcia merancho muestra la existencia de un derivado en -ancho del común mierda para un significado semejante a "canal de desagüe, lugar de agua estancada podrida". Aunque el vocablo no lo conocemos como tal salvo en la región de Murcia la toponimia muestra su presencia antigua en un territorio más amplio. El eufemismo lingüístico ha alterado en muchos casos la forma originaria y de esta manera son muchos los topónimos que pueden ser explicados mediante este vocablo y el sufijo -ancho o variantes: Maranchón, Belinchón, Berlinches, Berniches, etc. La viabilidad de la hipótesis recibe un último apoyo en la existencia, paralela, de topónimos que muestra exactamente el mismo significado mediante el empleo de un derivado del verbo cagar con exactamente el mismo sufijo que hemos visto en merdancho, merancho. Otra vez encontramos formas masculinas y femeninas alternando, otra vez aumentativos en -ón, otra vez se trata de nombres de arroyos o riachuelos de escaso caudal que han sido utilizados a menudo como meros estercoleros o cloacas: Arroyo de Cagancha (Esparragosa de la Serena, Badajoz) ${ }^{16}$, Arroyo Caganche (La Roca de la Sierra, Badajoz), Boca del Caganchín (Castilblanco, Badajoz), Cagancho (Higuera de Arjona, Jaén), Arroyo Caganchas (Belalcázar, Jaén), Río Caganchas (Hinojosa del Duque, Córdoba) ${ }^{17}$, etc.

\footnotetext{
${ }^{15}$ Como es sabido, las dos palabras, miel y mierda, por su vecindad fonética y su lejanía semántica, está muy unidas en la fraseología popular en expresiones del tipo "Pastel, pastel, y no precisamente de miel". En el caso de los Arroyo de la Miel sin duda hay ejemplos en los que la designación hace referencia a lo dulce y apetitoso de sus aguas, pero en otros creemos que hay alteración eufemística precisamente por lo contrario.

${ }^{16}$ Es notable en este caso el hecho de que conocemos el sustantivo común and. cagancho, "pájaro muy pequeño de colores café y negro". Es obvio que su motivación ("colores café y negro") es la misma que ha dado lugar a los topónimos citados aquí.

${ }^{17}$ Leemos en Orihuela Digital, con referencia a un merancho, lo siguiente: "La CHS (: Confederación Hidrográfica del Segura) pide a los Ayuntamientos. . . . vigilancia para que no se utilice los cauces como vertederos". Puede verse fotos de la acequia del Merancho llena de basuras en la dirección http:www.orihueladigital.es/ Orihuela/ merancho_150607.htm. La cuestión ha sido tratada, incluso, en el parlamento regional, en la que un diputado (sesión 18 de Abril de 2004) dijo: “... hoy esos azarbes, esos brazales, cuando traen agua, traen normalmente agua pestilente, agua contaminada, agua cuyo olor está causando...".
} 
5. Creemos que llegado al final de este breve trabajo puede concluirse que merced al estudio de la toponimia hemos podido ofrecer una explicación que juzgamos convincente del término dialectal murciano merancho, que a lo que parece conoció, en sus distintas variantes, una extensión más grande en otros tiempos. Al mismo tiempo, esta explicación ha servido para esclarecer un conjunto amplio de topónimos que hasta la fecha no habían recibido una explicación mínimamente satisfactoria. Por último, el trabajo ha mostrado la influencia de factores culturales y sociales en la lengua, así como una tradición popular de designación de cursos de agua escasos y sucios.

\section{Bibliografía}

Agustín, Margarita. 1985. Maranchón: el recuerdo del pasado. Tierra Molinesa 3: 16-17.

Alcalá Venceslada, Antonio. 1998. Vocabulario andaluz. Jaén: Universidad de Jaén (Madrid, Real Academia Española, 1951).

Balari i Jovany, Josep. 1899. Orígenes históricos de Cataluña. Barcelona: Establecimiento Tipográfico de Hijos de Jaime Jepús.

Calero López de Ayala, José Luis. 1987. Léxico alcarreño conquense. Aproximación al estudio etnológico de la comarca. Cuenca: Diputación Provincial de Cuenca.

Cerveró Pozo, Vicente. 1975. Repertorio de nombres geográficos. Toledo. Valencia: Anubar.

Chacón Berruga, Teudiselo. 1981. El habla de La Roda de la Mancha. Albacete: Instituto de Estudios Albacetenses.

Corriente, Federico. 1999. Diccionario de arabismos y voces afines en iberorromance. Madrid: Gredos.

García Soriano, Justo. 1932. Vocabulario del dialecto murciano. Con un estudio preliminar y un apéndice de documentos regionales. Madrid: C. Bermejo Impresor (Murcia, Editora Regional, 1980).

Gómez Ortín, Francisco. 1981. Vocabulario del noroeste murciano. Contribución lexicográfica al español de Murcia. Murcia: Editora Regional de Murcia.

González Blanco, Antonino.1985. Diccionario de toponimia actual de La Rioja. Murcia: Instituto de Estudios Riojanos \& Universidad de Murcia.

González Blanco, Antonino \& García García, Inmaculada. 1998. Repertorio alfabético de la toponimia de la región de Murcia. Murcia: Editorial KR. 
González Salgado, José Antonio. 2003. Vocabulario tradicional de Extremadura. Léxico de la agricultura y ganadería. Mérida: Editora regional de Extremadura.

López Navarro, María Asunción. 1979. Repertorio de nombres geográficos. Ávila. Zaragoza: Ediciones Anubar.

Martínez Martínez, María. 2011. La cultura del agua en la Murcia medieval (ss. $I X-X V$ ). Murcia: Universidad de Murcia.

Monge Molinero, Eusebio. 1993. Topónimos de la provincia de Guadalajara. Sigüenza: Edición del autor.

Nieto Ballester, Emilio. 2000. La toponimia de las fuentes en España: una nota sobre algunos resultados de lat. fonte. RFE 80: 395-406.

OC: Joan Coromines. 1989-1997. Onomasticon Cataloniae. Els noms de lloc i noms de persona de totes les terres de llengua catalana. Barcelona: Curial Edicions Catalanes/La Caixa (8 vol.).

Pharies, David. 1994. Origin of the Spanish -nch Suffixes. Iberoromania 40: $1-43$.

Pharies, David. 2002. Diccionario etimológico de los sufijos españoles y de otros elementos finales. Madrid: Gredos.

Plata Montero, Alberto. 2011. Las Salinas de Belinchón. Esplendor, abandono y nuevas perspectivas de futuro para las antiguas fábricas de sal. COIIM (Revista informativa del Colegio Oficial de Ingenieros de Madrid) 54: 20-28.

Ranz Yubero, José Antonio. 1996. Toponimia mayor de Guadalajara. Guadalajara: Alfoz.

Sánchez Miguel, Juan Manuel. 1998. Diccionario del habla toledana. Toledo: Instituto Provincial de Investigaciones y Estudios Toledanos/Diputación Provincial de Toledo.

Serrano Belinchón, José. 1994. Diccionario enciclopédico de la provincia de Guadalajara. Guadalajara: Aache.

Serrano Botella, Ángel. 1986. El diccionario Icue. Habla popular de Cartagena. Murcia: Ediciones Mediterráneo.

Toro y Gisbert, Miguel del. 2007. Voces andaluzas (o usadas por autores andaluces) que faltan en el Diccionario de la Real Academia Española (1920). Estudio preliminar de M. Galeote. Zaragoza: Sociedad Helvética de estudios hispánicos. Révue hispanique 116, 1920: 313-647.

Yago Andrés, María del Carmen. 1974. Repertorio de nombres geográficos. Guadalajara. Valencia: Anubar. 
